\title{
Changes in asthma prevalence: two surveys 15 years apart
}

\author{
M L BURR, B K BUTLAND, S KING, AND E VAUGHAN-WILLIAMS \\ MCR Epidemiology Unit, Cardiff
}

SUMMARY In 1973 a survey was conducted among 12 year old children living in a defined area of South Wales. In 1988 the survey was repeated in the same area, again among 12 year old children. Questionnaires were completed for all 965 children in the population sample; peak expiratory flow rates were performed on them all, and repeated (except for five children) after an exercise provocation test. The prevalence of a history of wheeze at any time had increased from $17 \%$ to $22 \%$, while that of a history of asthma at any time had increased from $6 \%$ to $12 \%$. Current asthma had increased from $4 \%$ to $9 \%$, but wheezing in the past year not attributed to asthma had remained at $6 \%$. The exercise provocation tests suggested that both mild and severe asthma had become more common. Increases had also occurred in the frequencies of a history of eczema (from $5 \%$ to $16 \%$ ) and of hay fever (from $9 \%$ to $15 \%$ ). It seems that the prevalence of asthma has risen, and that this cannot be wholly explained by a greater readiness to diagnose the disease.

There is some dispute as to whether the prevalence of childhood asthma is rising in Britain. ${ }^{1-3} \mathrm{~A}$ phenomenal rise has occurred in hospital admission rates, ${ }^{3}$ but this may be attributable to changes in admission policy. The consulting rates for patients attending general practitioners for asthma have also increased, ${ }^{4}$ but this may merely reflect a greater readiness to diagnose asthma in wheezing children. In the absence of serial surveys conducted in the same areas with the same methodology it is not clear whether the prevalence is really changing. This paper describes a survey of 12 year old school children living in the same areas of South Wales in which a similar survey was conducted 15 years before, using the same methodology - that is, questionnaires and exercise provocation tests.

\section{Subjects and methods}

The survey was first conducted in 1973 and the findings then have already been published. ${ }^{5}$ It was repeated in 1988 in the same schools as before, together with another school that had opened in one of the catchment areas during the interval. As before, children who lived in the defined catchment areas and attended state supported Anglican, Roman Catholic, or Welsh schools were also included. The population sample comprised the children in their first year of high school, their 12th birthdays falling during the current school year.

A short questionnaire was sent to the parents containing the same questions as those in the 1973 questionnaire. The children were seen in groups at their schools and the peak expiratory flow rates (PEFR) and heights measured. Exercise testing was carried out at the same time of year (April-July) and in the same way as in 1973, with two minor modifications. Firstly, any child who was unable to attain $70 \%$ of the PEFR predicted from the 1973 data (allowing for height) was not exercised then but asked to attend on another occasion in order to avoid provocation testing when bronchoconstriction was already present. Secondly, children who were currently taking treatment for asthma were exercised with the others; if their PEFRs did not fall by more than $15 \%$ they were asked to return for another exercise test when they had not taken treatment other than steroids (oral or inhaled) for at least eight hours. If the PEFR fell by $15 \%$ or more when the child had taken treatment within eight hours the exercise test was not repeated; this was in case exercise provocation in the absence of treatment produced severe bronchoconstriction. In 1973 all children who had taken treatment within five hours of the test were re-exercised on another occasion when they had not taken recent treatment, 
whatever the original results. The exercise test consisted of free running for six minutes in the school hall or gymnasium, followed by five minutes resting. Five PEFR values were recorded immediately before the exercise and at the end of the rest period, the mean of the three highest readings being taken as the true value on each occasion.

\section{Results}

A total of 965 children (495 boys, 470 girls) were identified as eligible for the survey. The number was higher than that in $1973(818)$ owing to residential developments and some changes in catchment areas of the schools. A questionnaire was completed for every child. Table 1 shows the percentages of children for whom various conditions were reported; a few errors in the 1973 data have been corrected, causing slight differences from the previously published figures. 'Current asthma' denotes the children ( 51 boys and 37 girls) who were said to have had asthma and to have wheezed during the past 12 months. The proportion reporting a history of asthma (currently or at any time) had doubled from the first to the second survey. The percentage reporting wheezing had also risen, but this increase was accounted for by the higher prevalence of asthma, the proportion with wheeze in the past 12 months but no asthma being about the same $(6 \%)$ on each occasion. The prevalence of a history of eczema had risen to an even greater extent (from $5 \%$ in 1973 to $16 \%$ in 1988 ), while hay fever had risen from $9 \%$ to $15 \%$.

Table 2 relates to those subjects who had ever wheezed. Certain factors were listed on the questionnaire as possible causes of wheezing. More than one factor could be selected, so the numbers are not mutually exclusive. There was a substantial rise in the prevalence of wheezing attributed to running, to contact with animals, and to food, and the propor-
Table 2 Attributed causes of wheezing in the two surveys

\begin{tabular}{|c|c|c|c|c|c|c|}
\hline \multirow{2}{*}{$\begin{array}{l}\text { Attributed } \\
\text { cause }\end{array}$} & \multicolumn{3}{|c|}{1973 Survey } & \multicolumn{3}{|c|}{1988 Survey } \\
\hline & No & $\begin{array}{l}\% \text { Of } \\
\text { all } \\
\text { children } \\
(n=817)\end{array}$ & $\begin{array}{l}\% \text { Of } \\
\text { wheezers } \\
(n=138)\end{array}$ & No & $\begin{array}{l}\% \text { Of } \\
\text { all } \\
\text { children } \\
(n=965)\end{array}$ & $\begin{array}{l}\% \text { Of } \\
\text { wheezers } \\
(n=215)\end{array}$ \\
\hline Colds & 125 & $15 \cdot 3$ & $90 \cdot 6$ & 166 & $17 \cdot 2$ & $77 \cdot 2$ \\
\hline Running & 47 & $5 \cdot 8$ & $34 \cdot 1$ & 101 & $10 \cdot 5$ & $47 \cdot 0$ \\
\hline Worry & 22 & $2 \cdot 7$ & $15 \cdot 9$ & 27 & $2 \cdot 8$ & $12 \cdot 6$ \\
\hline Excitement & 27 & $3 \cdot 3$ & $19 \cdot 6$ & 44 & $4 \cdot 6$ & $20 \cdot 5$ \\
\hline Animals & 14 & $1 \cdot 7$ & $10 \cdot 1$ & 35 & $3 \cdot 6$ & $16 \cdot 3$ \\
\hline Foods & 1 & $0 \cdot 1$ & 0.7 & 16 & 1.7 & $7 \cdot 4$ \\
\hline
\end{tabular}

Table 3 Changes in PEFR on exercise: cumulative percentages of children with $(P E F R 2 / P E F R 1) \times 100$ below various levels

\begin{tabular}{|c|c|c|c|c|}
\hline \multirow{2}{*}{$\begin{array}{l}(P E F R 2 / P E F R 1) \\
\times 100 \\
(\%)\end{array}$} & \multicolumn{2}{|l|}{1973 Survey } & \multicolumn{2}{|l|}{1988 Survey } \\
\hline & $\begin{array}{l}\text { Cumulative } \\
\%\end{array}$ & No & $\begin{array}{l}\text { Cumulative } \\
\%\end{array}$ & No \\
\hline$<25$ & - & 0 & $0 \cdot 2$ & 2 \\
\hline$<35$ & $0 \cdot 1$ & 1 & $0 \cdot 3$ & 3 \\
\hline$<45$ & 0.2 & 2 & $0 \cdot 8$ & 8 \\
\hline$<55$ & 0.4 & 3 & $1 \cdot 3$ & 12 \\
\hline$<65$ & 0.9 & 7 & $2 \cdot 3$ & 22 \\
\hline$<75$ & $2 \cdot 0$ & 16 & $4 \cdot 1$ & 39 \\
\hline$<85$ & $6 \cdot 7$ & 54 & $7 \cdot 7$ & 74 \\
\hline$<95$ & $36 \cdot 7$ & 298 & $30 \cdot 8$ & 296 \\
\hline$<105$ & 91.4 & 742 & $89 \cdot 0$ & 854 \\
\hline$<115$ & $99 \cdot 1$ & 805 & $99 \cdot 6$ & 956 \\
\hline$<125$ & 100 & 812 & 99.9 & 959 \\
\hline$<135$ & 100 & 812 & 100 & 960 \\
\hline
\end{tabular}

tion of wheezy children whose symptoms were attributed to these factors also increased. There was less change in the percentages attributing wheezing to worry or excitement; wheezy colds had a similar prevalence in the two surveys but declined as a proportion of all wheezy children.

Initial PEFR and height were measured in all 965

Table 1 Prevalence of history of symptoms in two surveys. Results are \%

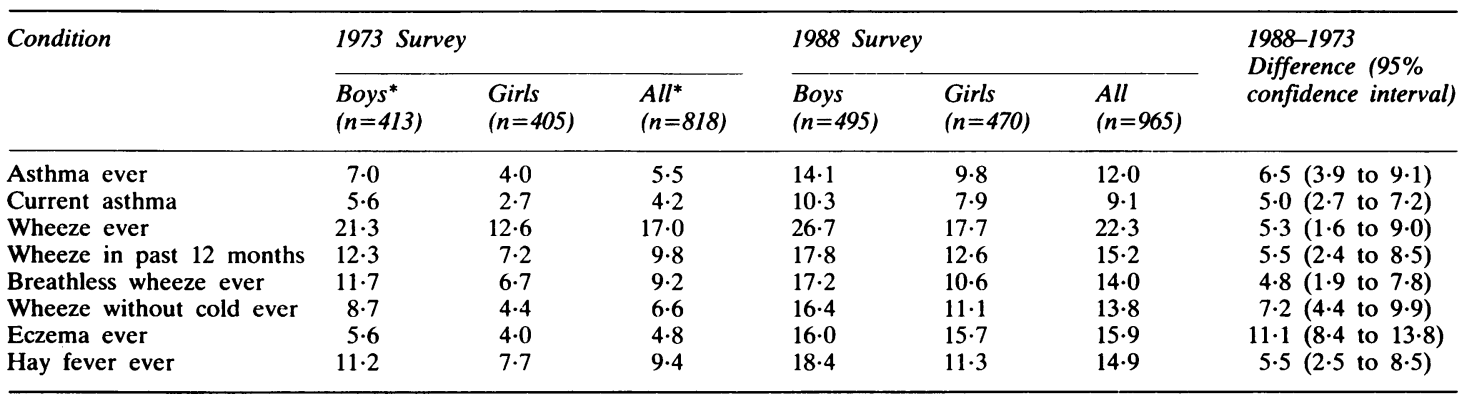

*Includes one boy with current asthma about whom no other information was obtained. 
children. The mean (SD) PEFR was 328 (58) $1 /$ minute in the boys with current asthma and 350 (48) $1 /$ minute in the other boys, the mean values for girls being 332 (58) and 351 (51) 1/minute respectively. The difference in boys was significant $(p<0.01)$ whereas in girls it just failed to reach significance $(t=1.94)$ using unpaired $t$ tests. Mean heights were $1470(64)$ and $1491(71) \mathrm{mm}$ for the asthmatic and non-asthmatic boys respectively, and 1498 (78) and 1509 (73) $\mathrm{mm}$ respectively for the asthmatic and non-asthmatic girls. When corrected for height (using simple linear regression), mean PEFR was 5\% lower in the boys with asthma than in those without $(p<0.05)$, and $4 \%$ lower in the girls with asthma than in those without, but this was not significant.

Five children did not exercise because of conditions other than asthma: one had currently treated asthma, one had wheezed during the past year, one had wheezed before the past year, and two had never wheezed. Four children could not attain $70 \%$
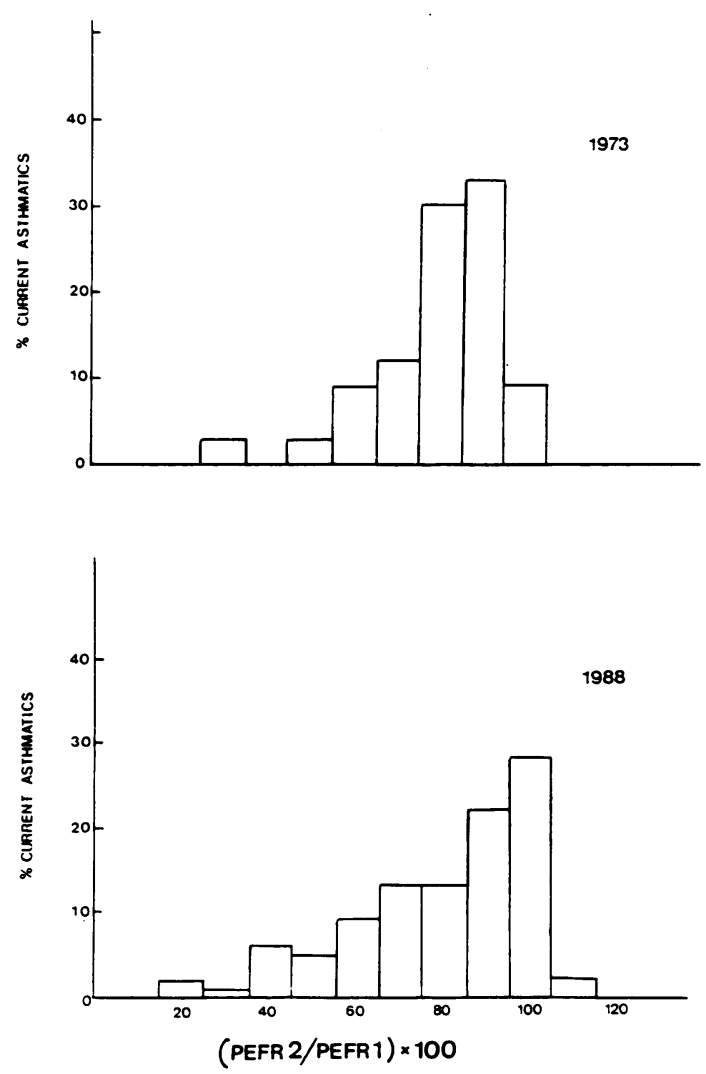

Fig 1 Effect of exercise on children with current asthma. of the predicted PEFR, so they were recalled and exercised on a further occasion when their PEFRs were higher. Of 39 children who had taken bronchodilators, cromoglycate, or inhaled steroids during the eight hours before the exercise test, 16 reexercised without treatment, three re-exercised having taken inhaled steroids only, and 20 did not re-exercise as their PEFRs fell by at least $15 \%$ on the first occasion. In the 1973 survey six children re-exercised because they had taken medication for asthma within the past five hours. In five of these cases the original PEFRs fell by more than $15 \%$ on exercise, so the results of the first exercise tests were used in comparisons with the 1988 survey as they would not have been re-tested had they been seen in 1988. Two other children in 1973 had taken cromoglycate during the eight hours before the test and were not retested; in one of these the PEFR fell
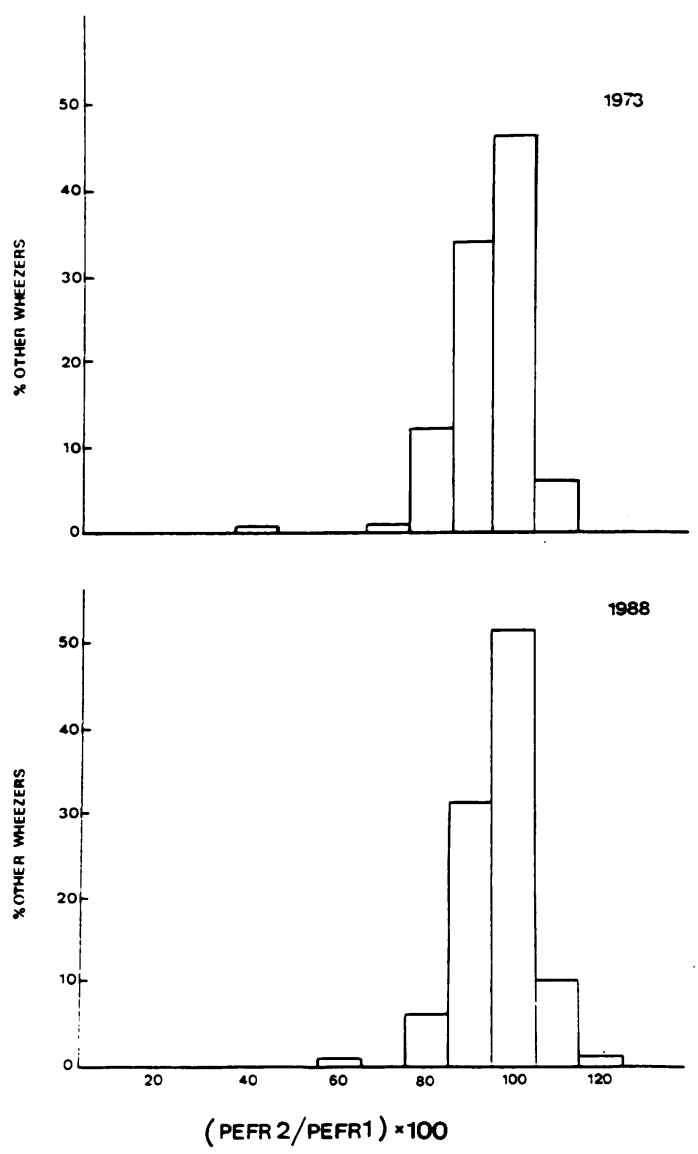

Fig 2 Effect of exercise on other children who had ever wheezed. 

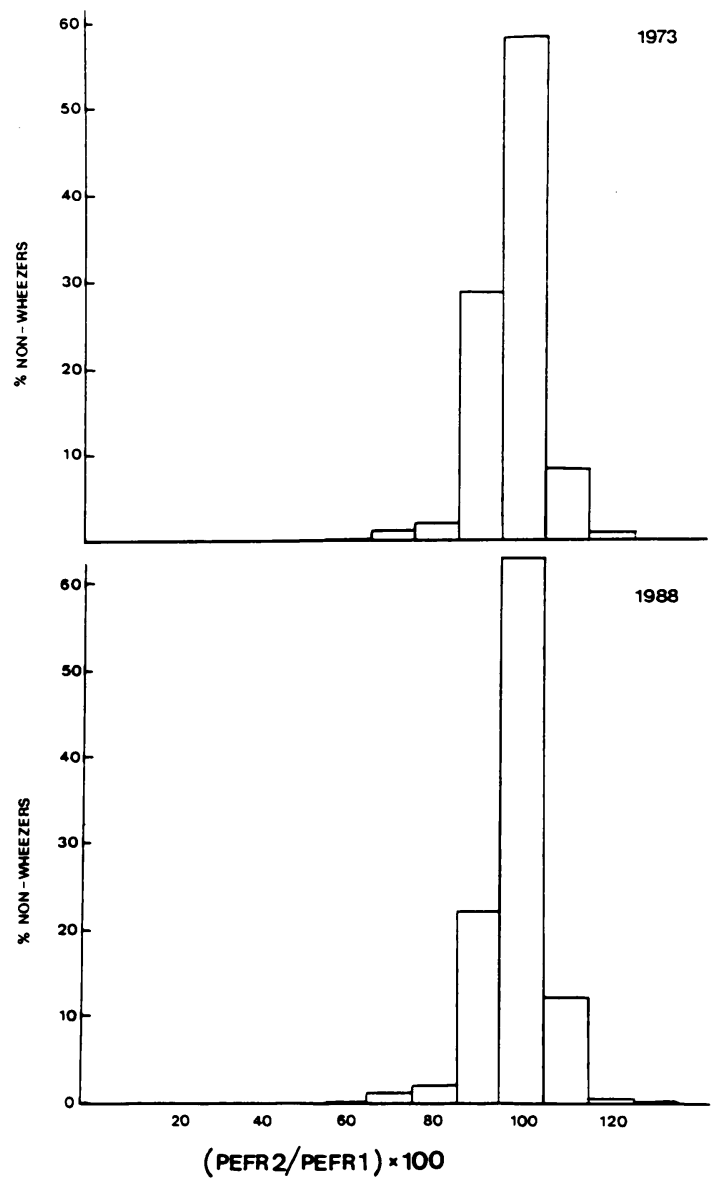

Fig 3 Effect of exercise on children who had never wheezed.

by more than $15 \%$ so the test would not have been repeated in 1988. Six did not exercise in 1973.

The PEFR measured after exercise was expressed as a percentage of the initial PEFR for each child: $($ PEFR2/PEFR1) $\times 100$. In both surveys there was no significant sex difference in the mean (PEFR2/ PEFR1) $\times 100$ among asthmatic or non-asthmatic children, so the data from boys and girls were combined. Table 3 shows cumulative percentages of the children in the two surveys with (PEFR2/ PEFR1) $\times 100$ values below various levels. A low value occurred more often in 1988 than in 1973 $(p<0 \cdot 05)$ : a value of $75 \%$ or less occurred twice as frequently in the second survey than in the first, and lower values showed an even greater disparity. In the middle and upper parts of the distribution the differences were less consistent.

Fig 1 shows the distribution of (PEFR2/PEFR1) $\times 100$ in the children with current asthma in the two surveys (33 in 1973, 87 in 1988). On each occasion there was a considerable skew to the left, and in 1988 the values were distributed more widely than in 1973. The mean value was very similar on the two occasions $(80.8$ in 1973 and 79.9 in 1988), but the variance was significantly greater $(p<0.01)$ in the second survey, the SD being 14.2 and 21.4 respectively.

Fig 2 shows the distributions of (PEFR2/PEFR1) $\times 100$ in the other children who had ever wheezed (105 in 1973, 125 in 1988). Here the 1988 distribution was somewhat more compact than that of 1973, with less of a leftward skew. The mean (SD) value was $93.5(9.2)$ in 1973 and $96.2(7.6)$ in 1988 , the difference in variance being significant at $p<0.05$. Data from the children who had never wheezed (674 in 1973, 748 in 1988) are shown in fig 3. The distributions showed little skew and were not dissimilar, but there was some tendency for values to be higher in the second survey; the mean values were $97.2(6.5)$ and $98.3(6.5)$ respectively.

\section{Discussion}

This survey was undertaken primarily to see whether the prevalence of asthma had changed since a similar survey 15 years ago. In 1973 only one child (known to have asthma) failed to participate, and in 1988 the response rate to the questionnaire was $100 \%$, so selective bias was avoided. The same investigator conducted both surveys, using exactly the same procedures except for slight modifications that involved very few children. It is therefore most unlikely that the differences in the findings could be attributable to any changes of methodology.

In several countries there has been some anxiety about a possible rise in asthma mortality during recent years, particularly among young people. ${ }^{6-9}$ The issue is complicated by changes in diagnostic practice and coding rules, and there is some dispute about the underlying trend. ${ }^{1-3}$ It is difficult to obtain accurate information about changes in the prevalence of asthma owing to the lack of a suitable definition. In the present study no attempt was made to define asthma; the prevalence of reported asthma and wheezing was compared on two occasions together with the response to a simple exercise challenge test.

The results are in accord with the reported increase in the number of people consulting general practitioners for asthma. ${ }^{4}$ The rise in asthma prevalence cannot be attributed solely to a change in diagnostic terminology, as the prevalence of wheezing not diagnosed as asthma has remained constant. As a further attempt to distinguish a genuine 
increase from a greater readiness to diagnose the disease, questions were asked about symptom patterns suggestive of asthma (wheezing with breathlessness in the absence of a cold, on running, or on contact with animals) without using the word 'asthma'. In each case the prevalence increased appreciably between 1973 and 1988. Among children who had ever wheezed, the proportion whose wheezing was attributed to running or animals had increased, again suggesting a real rise in asthma prevalence rather than better reporting of wheeze; the increased attribution to foods may perhaps simply reflect greater publicity given to food allergy now than in 1973. A fourfold rise occurred of children who had taken bronchodilators or other treatment for asthma within the eight hours before the interview, from eight $(1 \%)$ in 1973 to $39(4 \%)$ in 1988. This confirmed the impression of several of the school teachers, who remarked that the number of children taking treatment for asthma had greatly increased during the last few years.

There had also been an appreciable increase in children with histories of eczema (threefold) and hay fever (by about 50\%). Other studies have reported similar increases in these conditions during recent years. ${ }^{410}$ It is of course accepted that the actual figures are very imprecise, owing to the vagaries of memory and diagnostic fashion. But it seems very unlikely that the reporting of all three conditions would have increased to this extent and with this degree of consistency unless allergic disease was really becoming more common.

The exercise challenge provided some objective evidence in support of the questionnaire findings. Although a fall in PEFR of $25 \%$ or more was uncommon, it occurred more frequently in 1988 than in 1973, and the increase in the more severe reactions was proportionately even greater. Children said to have current asthma had a somewhat wider distribution of (PEFR2/PEFR1) $\times 100$ in 1988 than in 1973-that is, if the response to exercise indicates severity of asthma, both mild asthma and severe asthma had become more common. Among the other children with a history of wheeze, the leftward skew in 1988 was less than that in 1973. Taken together these changes suggest that there has been both a real increase in the prevalence of asthma and a tendency to diagnose asthma in 1988 among wheezy children who would previously have been regarded as non-asthmatic. The children who had never wheezed showed a similar pattern on the two occasions, except that the mean PEFR\% was slightly higher in 1988 .

It is not at all clear what factors could have caused the prevalence of asthma to rise. The genetic composition of the populations surveyed appeared to be unchanged; the area contained very few people of immigrant stock on either occasion. Atmospheric pollution has been associated with a higher prevalence of asthma, ${ }^{11}{ }^{12}$ but this is not an obvious problem in the area where this study was conducted. Studies of Xhosa children ${ }^{13}$ and Tokelau islanders ${ }^{14}$ suggest that the risk of asthma is associated with the modern western way of life. It may be that some environmental factor that provokes asthma has become more common during recent years. Alternatively a cohort effect has been postulated ${ }^{2}$ determined by factors operating near the time of birth. The identity of such factors can only be conjectured at present.

Similar surveys are being conducted in several other countries, and comparative findings will be presented in due course.

We are most grateful to the staff of the schools concerned in this survey for all their help and to the children for their participation.

\section{References}

${ }^{1}$ Burr ML. Is asthma increasing? J Epidemiol Community Health 1987;41:185-9.

2 Burney P. Asthma deaths in England and Wales 1931-85: evidence for a true increase in asthma mortality. $J$ Epidemiol Community Health 1988;42:316-20.

3 Anderson HR. Is the prevalence of asthma changing? Arch Dis Child 1989;64:172-5.

4 Fleming DM, Crombie DL. Prevalence of asthma and hay fever in England and Wales. Br Med $J$ 1987;294:279-83.

5 Burr ML, Eldridge BA, Borysiewicz LK. Peak expiratory flow rates before and after exercise in school children. Arch Dis Child 1974;49:923-6.

6 Jackson RT, Beaglehole R, Rea HH, Sutherland DC. Mortality from asthma: a new epidemic in New Zealand. Br Med $J$ 1982;285:771-4.

7 Stewart CJ, Nunn AJ. Are asthma mortality rates changing? $\mathrm{Br}$ J Dis Chest 1985;79:229-34.

${ }^{8}$ Markham D, Chang M, Evans R, Mulally D. Epidemiologic study of deaths from asthma among children in US 1965-1983. J Allergy Clin Immunol 1986;77:161.

9 Burney PGJ. Asthma mortality in England and Wales: evidence for a further increase. Lancet 1986;ii:323-6.

10 Taylor B, Wadsworth J, Wadsworth M, Peckham C. Changes in the reported prevalence of childhood eczema since the 1939-45 war. Lancet 1984;ii:1255-7.

$"$ Andrae S, Axelson O, Bjorksten B, Fredriksson M, Kjellman $\mathrm{N}$-IM. Symptoms of bronchial reactivity and asthma in relation to environmental factors. Arch Dis Child 1988;63:473-8.

12 Goren AI, Hellmann S. Prevalence of respiratory symptoms and diseases in school children living in a polluted and in a low polluted area in Israel. Environ Res 1988;45:28-37.

13 Van Niekerk CH, Weinberg EG, Short SC, Heese HdeV, van Schalkwyk DJ. Prevalence of asthma: a comparative study of urban and rural Xhosa children. Clin Allergy 1979;9:319-24.

14 Waite DA, Eyles EF, Tonkin SL, O'Donnell TV. Asthma prevalence in Tokelauan children in two environments. Clin Allergy 1980;10:71-5.

Correspondence and requests for reprints to Dr ML Burr, MRC Epidemiology Unit, 4 Richmond Road, Cardiff CF2 3AS.

Accepted 11 May 1989 